Patientenmanagement bei Krankenhausinfektionen

\title{
Molekulare Diagnostik bietet schnelle Ergebnisse
}

\begin{abstract}
- Krankenhausinfektionen, insbesondere durch multiresistente Erreger, sind ein zunehmendes Problem. Dabei geht es insbesondere darum, solche mittels ScreeningMethoden frühzeitig zu erkennen, um dann durch geeignete Maßnahmen Transmissionen und Infektionen zu verhindern. Vorteilhaft sind molekulare Verfahren wie die Polymerasekettenreaktion (PCR). „Die PCRTechnologie zeichnet sich durch eine sehr hohe Spezifität und Sensitivität und eine deutlich kürzere Turn-around-Zeit aus", erläuterte Dr. Oliver Liesenfeld, Chief Medical Officer von Roche Molecular Systems. Gerade für das MRSA-Screening sei es wichtig, dass das Ergebnis sehr schnell vorliege. Bei einer molekularen Diagnostik ist das nach max. 30 Minuten der Fall. Bei den chromogenen Kulturmedien vergehen dagegen mindestens 24 Stunden.
\end{abstract}

Mit dem neuen cobas $^{\circledast}$ Liat $^{\oplus}$ System steht jetzt eine leicht zu bedienende Molekulardiagnostikplattform zur Verfügung. „Das handliche System erleichtert die Diagnose von Infektionskrankheiten und erlaubt zentral und dezentral schnelle Entscheidungen", so Liesenfeld. Innerhalb kurzer Zeit könne das Labor Einzelproben auch außer- halb der üblichen Betriebszeiten und auch in Außenstellen wie dem Notfall-Labor bearbeiten. Das ermögliche Ärzten, schnelle Therapieentscheidungen treffen und entsprechende Hygienemaßnahmen einleiten zu können.

Das Test-Portfolio umfasst zurzeit Influenza A/B, Influenza A/B + RSV, Strep A und Clostridium difficile. In absehbarer Zeit wird MRSA/SA folgen; HIV qual. ist in der Entwicklung. Im Vergleich zur Virenkultur und IFA-Färbung beträgt die Sensitivität beim Influenza A/B Test $100 \%$ bei einer Spezifität von $96.8 \%$ bei Influenza A und $94.2 \%$ bei Influenza B. „Die gleichzeitige Detektion und Differenzierung von Influenza $A$ und $B$ in einem Test mit einem zuverlässigen Ergebnis bereits nach 20 Minuten ist ein großer Fortschritt", so Liesenfeld. Darüber hinaus bietet cobas ${ }^{\circledR}$ Liat $^{\circledR}$ ein umfangreiches Kontroll- und Sicherheitskonzept. (sti)

Satellitensymposium „cobas Liat: Schnelle Antworten - damit Infektionen sich nicht ausbreiten" im Rahmen der gemeinsamen Jahrestagung der Deutschen Gesellschaft für Hygiene und Mikrobiologie (DGHM) und der Vereinigung für Allgemeine und Angewandte Mikrobiologie (VAAM); Würzburg, 6.3.2017 (Veranstalter: Roche Diagnostics Deutschland $\mathrm{GmbH}$ )
Neuer Geschmack

\section{Zitronenfrische Trinknahrung}

_ Fresubin ${ }^{\circledast}$ YoDrink Lemon ist eine hochkalorische und eiweißreiche Trinknahrung und ergänzt im Mischkarton die bereits eingeführten Geschmacksrichtungen Himbeere und Aprikose-Pfirsich. Das vollbilanzierte Produkt kann zur ausschließlichen Ernährung verwendet werden und ist verordnungsfähig. Trinknahrungen sollen Nährstoffdefizite ausgleichen, wenn eine normale Ernährung dazu nicht ausreicht. Fresubin ${ }^{\circledast}$ YoDrink kann direkt aus der Easy Drink Flasche mit Trinkhilfe getrunken werden und schmeckt gekühlt am besten.

www.fresenius-kabi.de

\section{Erlanger Ernährungskonvent}

\section{Mangelernährung bei Kindern auf der Spur}

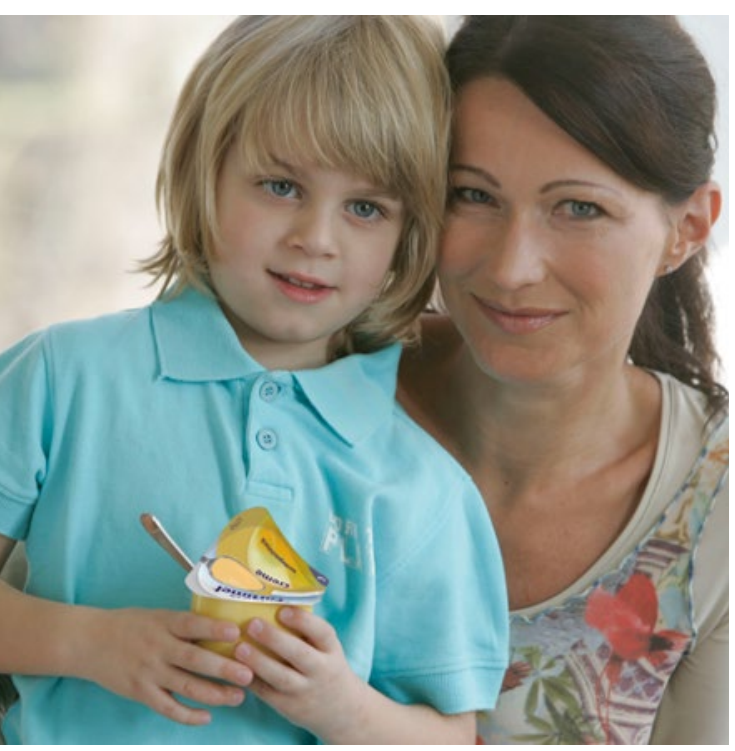

— Mehr Aufmerksamkeit für den Ernährungszustand besonders von chronisch kranken Kindern forderten Experten aus Klinik und Praxis, Ernährungsspezialisten und Vertreter von Pflege und Politik beim 3. Erlanger Ernährungskonvent. Ein besonders hohes Risiko für einen schlechten Ernährungszustand haben Frühgeborene und chronisch kranke Kinder. Die Folgen einer Mangelernährung können gravierend sein: Es kann u.a. zu Wachstumsstörungen, verminderter Gehirnentwicklung, erhöhter Infektanfälligkeit und einer verschlechterten neuromuskulären Entwicklung kommen.

Für einen individualisierten Ansatz bei der Ernährung akut und chronisch kranker Kinder setzt sich das Erlanger Unternehmen Nutricia ein. Es bietet dafür altersadaptierte pädiatrische Trink- und Sondennahrung, die speziell auf den individuellen Nährstoffbedarf von Kindern zugeschnitten ist. Die Infatrini ${ }^{\oplus}$-Produkte umfassen Trink- und Sondennahrung für Säuglinge. Für Kinder in den unterschiedlichen Entwicklungsphasen stehen verschiedene Varianten der Marke Nutrini ${ }^{\circledast}$ zur Verfügung. Auf der Internetseite von Nutricia sind auch Hinweise zur Arzneimittelrichtlinie bezüglich der Erstattung von medizinischer Ernährung zu finden. Zusätzlich bietet Nutricia einen deutschlandweit einmaligen Service an: Die MEHRnährungsexperten Junior unterstützen Eltern, Angehörige und Pflegekräfte von Kindern, die auf Trink- und/oder Sondennahrung angewiesen sind. Erfahrene, examinierte Pflegekräfte helfen unter anderem bei der Integration der Ernährungstherapie in den Familienalltag.

www.nutricia.de 